\title{
¿Escuchando mercaderes o escuchando abogados? La regla sobre producción de documentos en el arbitraje comercial
}

\author{
Huáscar Ezcurra * \\ Eduardo Iñiguez ${ }^{* *}$
}

Resumen. - Los autores muestran su preocupación por la manera en que los abogados, de manera inconsciente, diseñan los lineamientos correspondientes al arbitraje al escoger como regla predeterminada la producción de documentos amplia. Se propone optar por una producción de documentos específicos en miras a hacer del arbitraje un mecanismo de resolución de conflictos más eficiente para los clientes, más conocidos como "hombres de negocio".

\begin{abstract}
The authors express their concern for the way in which lawyers are establishing arbitration's rules by choosing as its main rule the full disclosure of documents. Their approach consists in switching the criteria and adopting a detailed disclosure of documents instead as a way of making arbitration a more efficient mechanism and therefore more suitable for the clients, also known as "business men".
\end{abstract}

Palabras claves. - Producción de documentos, arbitraje, principios del arbitraje comercial internacional.

Keywords. - Discovery, arbitration, principles of international commercial arbitration.

* Abogado por la Pontificia Universidad Católica del Perú. Máster en Derecho (LL.M.) por la Universidad de Yale. Profesor de Justicia sin Estado en la Facultad de Derecho de la Universidad del Pacífico y de Análisis económico del Derecho en la Maestría de Derecho Administrativo Económico de la Universidad del Pacífico. Profesor visitante de Análisis económico del Derecho de la Escuela Superior de Economía y Negocios de El Salvador. Socio de Bullard Falla Ezcurra +. Contacto: hezcurra@bullardabogados.pe.

** Bachiller por la Pontificia Universidad Católica del Perú. Director del área de Persuasión y Sistema de Justicia en PsychoLAWgy. Asociado de Bullard Falla Ezcurra +. Contacto: einiguez@bullardabogados.pe. 


\section{Introducción}

El arbitraje está dominado por abogados, no cabe duda. Los abogados redactan y proponen las normas que, luego, conformarán las leyes arbitrales. Los abogados dirigen las instituciones arbitrales. Los abogados igualmente proponen las normas que luego se convierten en los reglamentos arbitrales de los centros. Los árbitros, en gran mayoría, son abogados. Y, por supuesto, los abogados conducen los procedimientos arbitrales que sus clientes les encargan. Lo anterior, en buena parte, determina que el procedimiento arbitral haya sido diseñado y modelado de acuerdo a las necesidades y preferencias de los abogados.

Los abogados, en ese sentido, determinamos el "producto" de nuestra industria ¿Es eso bueno para la industria arbitral? En alguna medida sí es bueno, pues eso nos asegura que el "producto" (entendido como el proceso arbitral) responderá a las necesidades de nuestros clientes (si se tiene en cuenta que nuestro interés es fundamentalmente satisfacer sus necesidades).

No obstante, puede que, en algunos aspectos, los abogados no estemos escuchando claramente las demandas de nuestros clientes, sobre todo, si se trata de demandas que pudieran entrar en conflicto con nuestros intereses. Y si esto ocurre podrían generarse problemas, pues nuestro "producto" podría dejar de ser atractivo para nuestros clientes, que son a quienes finalmente nos debemos, y ante quienes dicho "producto" debe funcionar.

En suma, como en cualquier industria, en el arbitraje también, debemos escuchar atentamente, siempre, las demandas del consumidor de nuestro "producto".

El "producto" (el procedimiento arbitral) es un proceso diseñado para administrar eficientemente la resolución de disputas entre "hombres de negocios" (nuestros clientes), quienes usualmente prefieren procesos para una decisión definitiva de su disputa, con bajo costo y rapidez. Los "hombres de negocio" quieren continuar haciendo negocios. No pueden detener sus negocios y distraerse para dedicar su atención a un largo y costoso proceso arbitral.

Este artículo trata sobre los problemas y distorsiones que la llamada "producción de documentos" causa al proceso arbitral. La producción de documentos se ha convertido en una etapa que afecta directamente los costos y los tiempos del proceso, convirtiéndolos en procesos más costosos y más largos. La etapa de producción de documentos causa, justamente, lo que los "hombres de negocio" no quieren. Nuestra opinión es que la producción de documentos no aporta beneficios a la "búsqueda de la verdad" que justifiquen su costo. La producción de documentos se ha convertido en una institución que, para nuestros clientes, no vale lo que cuesta. Aunque para los abogados sí pudiera tener mucho valor, pues las horas facturables por esta etapa del proceso puede ser muy importantes.

Existe entonces un conflicto entre lo que es mejor para los abogados a cargo del proceso, y lo que es mejor para sus clientes. Nuestra opinión es que las reglas 


\section{¿Escuchando mercaderes o escuchando abogados? \\ La regla sobre producción de documentos en el arbitraje comercial}

actuales, así como el predominio de los abogados en el diseño del "producto" de la industria, determinan que se mantenga una regla que para los "hombres de negocio" causa más costo que beneficio. Los abogados no somos necesariamente conscientes de este conflicto, y de que ponemos nuestros intereses por encima de los de nuestros clientes. Muchos incluso hasta podrán creer sinceramente que la "búsqueda de la verdad" justifica plenamente tener siempre una etapa de producción de documentos. Por ello creemos que es fundamental escuchar a los hombres de negocio (a nuestros clientes), y para ese fin las encuestas que realizan Queen Mary University y White \& Case son fundamentales. Son nuestros clientes los que debieran tener la palabra final sobre si esta etapa de producción de documentos vale lo que cuesta.

En este trabajo nos preguntamos precisamente cuál debería ser la regla sobre "producción de documentos" en el arbitraje comercial. Y para responder esta pregunta, fundamentalmente, escuchamos la demanda de los hombres de negocio (nuestros clientes).

Para una mejor comprensión de cuál ha sido la demanda de los hombres de negocios, así como cuál fue el rol de los abogados en el proceso de resolución de disputas, hagamos un poco de historia.

En el siglo XI los mercaderes preferían que fueran otros mercaderes los que decidieran sobre sus disputas ${ }^{1}$. Los mercaderes favorecían un proceso diseñado y conducido para responder eficientemente a sus necesidades ¿Por qué los mercaderes preferían que sus disputas sean resueltas por otros mercaderes? Porque los mercaderes conocían mejor que nadie las necesidades y demandas de los propios mercaderes. Los mercaderes eran mejores "escuchando" las necesidades de los mercaderes y resolvían las disputas tomándolas en cuenta. Los mercaderes, en ese sentido, resolvían las disputas con suma celeridad. Como buenos hombres de negocio entendían la necesidad de continuar haciendo negocios, evitando que una disputa distrajera su atención y recursos.

Para ese mismo fin los mercaderes necesitaban un proceso flexible, justo y rápido. Un proceso en el que las ganancias justificaran claramente sus costos. La resolución de disputas comerciales debía respetar esa esencia. Debía ser eficiente. La velocidad fue parte importante de esa eficiencia. La resolución lenta y costosa de disputas no era ni eficiente ni justa.

En la Edad Media los mercaderes preferían una justicia sin Estado, considerando que la combinación de abogados y el rey usualmente resultaba en procedimientos sobre regulados, largos y costosos ${ }^{2}$. De hecho, los mercaderes no querían que los

1 COHEN, Julius Henry. Commercial Arbitration and the Law. Nueva York: D. Appleton and Company, 1918.

2 BLACKSTONE, William. Commentaries on the Laws of England: Book III. Oxford: Clarendon Press, 1768, citado en WOLAVER, Earl. "The Historical Background of Commercial Arbitration". En Univeristy of Pennsylvania Law Review, vol. 83, núm. 2, 1934, pp. 132-136. 
abogados sean parte de sus procesos ${ }^{3}$. Los abogados hacían todo siempre más complejo. Cuando los abogados aparecían, las apelaciones aparecían también, las objeciones, las recusaciones, etc. Con abogados participando, un proceso diseñado inicialmente para ser conducido por mercaderes se convirtió en un proceso conducido por abogados. Y los abogados, poco a poco, dejamos de "escuchar" a los hombres de negocios (a nuestros clientes).

Cabe entonces preguntarse si la actual regla sobre "producción de documentos" es una que responde a las necesidades de los hombres de negocios ¿Estamos realmente "escuchando" atentamente las necesidades de los usuarios del arbitraje o hemos dejado de escuchar?

En lo que sigue (i) explicaremos qué es la producción de documentos en el arbitraje comercial, (ii) por qué es importante la elección de una regla predeterminada o default, (iii) cuál es el principal problema de la producción de documentos en el arbitraje, (iv) cómo la producción de documentos como regla predeterminada contradice varios principios del arbitraje comercial internacional y (v) en qué consiste nuestra propuesta de regla predeterminada sobre producción de documentos en el arbitraje.

\section{La producción de documentos en el arbitraje comercial: ¿el choque de dos mundos?}

La producción de documentos tiene una larga tradición en los procesos judiciales de los países de common law. Y es un elemento prácticamente inexistente en el proceso judicial del civil law.

El discovery es un elemento indispensable en el proceso judicial del common law 4 . En Estados Unidos, es un mecanismo mediante el cual las partes de un proceso obtienen información de su contraparte antes del juicio ${ }^{5}$. Para obtener esa información, las partes pueden solicitar (i) un discovery de documentos, que consiste en la revelación de documentos solicitados por su contraparte ${ }^{6}$, (ii) una declaración o deposition, que es el testimonio de un testigo dado bajo juramento, afuera de la corte y con la presencia de los abogados de ambas partes7, (iii) un interrogatorio, que consiste en una lista de preguntas escritas que la otra parte debe responder por escrito y bajo juramento ${ }^{8}$ y (iv) solicitudes de admisión, mediante la cual una parte solicita a la otra negar o admitir una afirmación 9 .

3 BORN, Gary. International Commercial Arbitration. Países Bajos: Kluwer Law Interntional 2014, 2 da edición, p. 31.

4 GREENBERG, Simon, KEE, Christopher \& Weeramantry, Romesh. International Commercial Arbitration: An Asia-Pacific Perspective. Cambridge: Cambridge University Pres, 2011.

5 LAURENCE, William. Beweiserhebung in internationalen Schiedsverfahren. Alemania: Heymanns, 2001, p. 14.

6 MARGHITOLA, Reto. Document Production in International Arbitration. Países Bajos: International, Wolters Kluwer, 2015, p. 9.

7 Federal Rules of Civil Procedure, Rule 30 (Estados Unidos).

8 Federal Rules of Civil Procedure, Rule 33 (Estados Unidos).

9 Federal Rules of Civil Procedure, Rule 36 (Estados Unidos). 


\section{¿Escuchando mercaderes o escuchando abogados? \\ La regla sobre producción de documentos en el arbitraje comercial}

En Inglaterra, se emplea el término disclosure que se traduce en "revelación"10. Se diferencia del sistema norteamericano en que una parte tiene la obligación de revelar una lista de todos los documentos que posee en relación con esa disputa, sea que beneficien o perjudiquen su caso $^{11}$. La contraparte tiene derecho a inspeccionar los documentos declarados por su contraparte ${ }^{12}$, salvo que estén sujetos a algún privilegio o secreto profesional ${ }^{13}$.

La importancia del discovery en el common law se explica desde el objetivo perseguido por el sistema judicial. El objetivo del proceso del common law es descubrir la verdad ${ }^{14}$. En ese sentido, el resultado de un proceso no puede ser considerado justo si en él no se ha descubierto la verdad ${ }^{15}$. Igualmente, una parte no debería tener la posibilidad de beneficiarse por esconder un documento relevante ${ }^{16}$. Como señala la Corte de Apelaciones de Inglaterra, el objetivo del discovery es poner "las cartas sobre la mesa"17.

El Discovery también se explica desde la estructura del proceso judicial en el common law. A diferencia del proceso del civil law, los escritos en el common law suelen ser breves (ni largos ni complejos) ${ }^{18}$, y las partes no están obligadas a presentar conjuntamente con sus escritos todos los documentos que consideren relevantes ${ }^{19}$. Por tanto, típicamente, una parte no puede saber sobre qué documentos su contraparte ha construido su caso. Recién lo sabrá en las audiencias orales. En ese sentido, el discovery o disclosure, que es anterior al juicio, precisamente permite que esa parte no se vea sorprendida durante las audiencias con documentos que nunca ha visto o que no ha tenido la oportunidad de ver

10 MATTHEWS, Paul y MALEK, Hodge. Disclosure. Londres: Sweet \& Maxwell , 2007, 3ra Edición.

11 ADLER, Derek y JOHNSON, Adam. "Overview of Litigation in the United States and England". En FELLAS, John, Transatlantic Commercial Litigation and Arbitration, Nueva York: Oceana Publications, 2004, 1ra Edición.

12 DAVIES, Valerie \& PIEPER, Thomas. “English Disclosure and U.S. Discovery". En FELLAS, John, Transatlantic Commercial Litigation and Arbitration, Nueva York: Oceana Publications, 2004, 1ra Edición, p. 257.

13 ADLER, Derek y JOHNSON, Adam. "Overview of Litigation in the United States and England". En FELLAS, John, Transatlantic Commercial Litigation and Arbitration. Nueva York: Oceana Publications, 2004, 1ra Edición, p. 18.

14 MARGHITOLA, Reto. Document Production in International Arbitration. Países Bajos: International, Wolters Kluwer, 2015, p. 12.

15 BROWER, Charles y SHARPE, Jeremy. "Determining the Extent of Discovery and Dealing with Requests for Discovery: Perspectives from the Common Law". En NEWMAN, Lawrence y HILL, Richard (eds.), The Leading Arbitrators' Guide to International Arbitration, JurisNet- LLC, 2014, 3ra Edición, p. 594.

16 PINKSTON, Jarred. “The Case for a Continental European Arbitral Institution to Limit Document Production". En KLAUSEGGER, Christian, Austrian Yearbook on International Arbitration, Austria: Manz, 2011, p. 87.

17 Davies vs. Eli Lilly \& Co. and Others, [1987] 1 WLR 428, 431(EWCA) (Eng.).

18 ARMAS, Oliver y SMITH, George Bundy. "The Impact of U.S. Litigation”. En CARTER, James y FELLAS, John (eds.), International Commercial Arbitration in New York, Nueva York: Oxford University Press, 2010, p. 55.

19 REED, Lucy y HANCOCK, Ginger. “US-Style Discovery: Good or Evil?”. En Giovannini, Teresa y Mourre, Alexis (eds.), Written Evidence and Discovery in International Arbitration: New Issues and Tendencies, Países Bajos: Kluwer Law International, 2009, p. 342. 
antes 20.

En el civil law la lógica del proceso es distinta. Aun cuando pueda afirmarse que en el proceso del civil law también se busca la verdad, en estos sistemas el énfasis está puesto en la carga de la prueba ${ }^{21}$ como medio para alcanzar esa finalidad. Cada parte tiene la carga de probar sus pretensiones ${ }^{22} \mathrm{y}$, en ese sentido, cada parte tiene la responsabilidad de presentar y sustentar su verdad. Si no se satisface la carga de la prueba las pretensiones formuladas serán rechazadas por el juez. Como consecuencia de lo anterior, cada parte presentará y sustentará su caso con los documentos que tenga en su poder.

Bajo el civil law la estructura de los procesos judiciales no admite una figura como el discovery del common law. En los procesos del civil law cada parte tiene plazos específicos para presentar sus escritos, los cuales deben ser presentados junto a los documentos en los que se sustenta el caso $^{23}$. Si las partes fallan en aportar documentos hasta determinada etapa del proceso, estos simplemente no serán tomados en cuenta (salvo excepciones muy puntuales).

Bajo esta lógica, el discovery norteamericano o el disclosure inglés son un medio para aliviar la carga de probar de las partes. Eso no ocurre bajo el civil law donde la carga de la prueba es el medio a través del cual cada defensa presenta su verdad. En este caso cada parte sabe que los únicos documentos sobre los que puede resolver el juez son los que han sido presentados junto a sus respectivos escritos. No hay lugar para sorpresa en alguna fase posterior del proceso.

Lo que sí existe en el civil law es un muy limitado mecanismo de "producción de documentos", que usualmente requiere la identificación precisa de documentos específicos de la contraparte ${ }^{24}$. No es posible pedir categorías de documentos o documentos dentro de un período de tiempo, pues eso iría en contra del principio de la carga de la prueba.

¿Y qué existe en el arbitraje comercial? En el arbitraje comercial no encontramos ni uno ni otro realmente. La práctica en el arbitraje comercial internacional, por un lado, no suele aceptar un deber general de disclosure como en el sistema inglés 25 ; tampoco suele aceptar mecanismos como declaraciones, interrogatorios o solicitudes de admisión, antes de presentar la demanda, como ocurre bajo el

20 MARGHITOLA, Reto. Document Production in International Arbitration. Países Bajos: International, Wolters Kluwer, 2015, p. 13.

21 SCHWARZ, Franz T. y KONRAD, Christian. The Vienna Rules: A Commentary on International Arbitration in Austria. Países Bajos: Kluwer Law International, 2009, n. 20-237.

22 CECCON, Roberto. "UNCITRAL Notes on Organizing Arbitral Proceedings and the Conduct of Evidence: A New Approach to International Arbitration". En Journal of Internaitional Arbitration, vol. 14, núm. 2, 1997, p. 69.

23 DEMEYERE, Luc. "An Essay on Differing Approaches to Procedures under Common law And Civil Law". En German Arbitration Journal, 2008, pp. 279- 282.

24 ANGELL, Jorge. "Spain". En EIJSVOOGEL, Peter (ed.), Evidence in International Arbitration Proceedings, Londres: Graham \& Trotman, 1994, p. 227.

25 MARGHITOLA, Reto. Document Production in International Arbitration. Países Bajos: International, Wolters Kluwer, 2015, p. 10. 


\section{¿Escuchando mercaderes o escuchando abogados? \\ La regla sobre producción de documentos en el arbitraje comercial}

sistema norteamericano $26 ; \mathrm{y}$, finalmente, tampoco suele limitar la producción de documentos (cuando la hay) a la identificación de documentos específicos (como ocurre en el civil law $)^{27}$.

La producción de documentos en el arbitraje comercial es un mecanismo mediante el cual una parte se ve obligada a presentar determinados documentos que se encuentran en su posesión. De lo contrario, un tribunal arbitral podría generar inferencias adversas. Usualmente será la contraparte la que solicite la producción de documentos ${ }^{28}$. El pedido de documentos normalmente no se verá limitado a la solicitud de documentos específicos, pudiendo pedirse categorías de documentos (pero sí estará limitado por determinados parámetros).

Por supuesto, dada la naturaleza flexible del arbitraje, el procedimiento de producción de documentos variará de arbitraje en arbitraje ${ }^{29}$, dependiendo de factores como la tradición legal de la que vienen las partes, de la que vienen los árbitros o de las reglas pactadas.

A diferencia del common law, donde el proceso persigue encontrar la verdad y está diseñado de tal manera que sin discovery o disclosure las partes podrían verse afectadas; o a diferencia del civil law, donde el proceso pone la carga de la prueba en las partes y el mismo ha sido diseñado de tal manera que la producción de documentos es solo necesaria excepcionalmente; la flexibilidad del arbitraje permite que en determinados casos la producción de documentos juegue un papel, y que en otros casos juegue un papel diferente.

Por ejemplo, en un caso que involucra a dos partes norteamericanas, con tres árbitros norteamericanos y cuyas reglas procedimentales se asemejan a la de un proceso judicial del common law (sin escritos grandes, sin obligación de anexar documentos, etc.), imaginar ese arbitraje sin discovery parece imposible.

En el caso contrario, si un arbitraje involucra a dos partes del civil law, con tres árbitros de la misma tradición y cuyas reglas son más parecidas a las de un proceso civil, el rol que puede cumplir la producción de documentos en ese procedimiento parece muy distinto y muy inferior.

No parece entonces que la producción de documentos en el arbitraje internacional sea hoy el producto o compromiso de un "choque de culturas". Parece más bien que reglas distintas sobre producción de documentos serán necesarias para distintos arbitrajes, según el caso.

26 ELSING, Siegfried y Townsend, John. "Bridging the Common Law-Civil Law Divide in Arbitration". En Arbitration International, vol. 18, núm. 1, 2002, p. 61.

27 MARGHITOLA, Reto. Document Production in International Arbitration. Países Bajos: International, Wolters Kluwer, 2015, p. 18.

28 Por ejemplo, Artículo 27.3. del Reglamento de Arbitraje de Comisión de las Naciones Unidas para el Derecho (CNUDMI).

29 FINIZIO, Steven. "Discovery in International Arbitration: Frankenstein's Monster in the Digital Age”. En Böckstiegel, Karl-Heinz; Berger, Klaus-Peter y Bredow, Jens (eds.), The Taking of Evidence in International Commercial Arbitration, Colonia: Carl Heymanns, 2010, p. 59. 
Sin embargo, tiene que haber una regla default, aplicable cuando las partes no logran ponerse de acuerdo. Y la regla default es una a favor de que exista producción de documentos (salvo que las partes pacten lo contrario o que el tribunal así lo decida). Esto ocurre usualmente cuando, ante falta de acuerdo, y habiendo una parte a favor de la producción de documentos, y otra en contra, los Tribunales arbitrales suelen preferir incluir una etapa de producción de documentos, pues ante la discrepancia de las partes, preferirán aquella regla que favorezca la búsqueda de la verdad, o aquella regla que favorezca la posibilidad de que las partes tengan amplia oportunidad de probar su cas

Cabe entonces preguntarse $¿$ si las partes hubieran tenido la posibilidad de llegar a un acuerdo sobre este asunto, hubieran acordado incluir una etapa de producción de documentos en el proceso?

\section{La importancia de la regla default}

Podría pensarse que proponer una regla default o predeterminada es un ejercicio innecesario, pues las partes siempre pueden pactar en contra de esa regla. Nada más alejado de la realidad. Desde hace mucho tiempo, la teoría económica ha destacado la importancia de las reglas default en el derecho de los contratos. Asimismo, la psicología ha aportado mayores razones para elegir reglas predeterminadas adecuadas. Esto es especialmente cierto en el arbitraje.

Una regla default o predeterminada es aquella que puede ser modificada por las partes, pero que será aplicada si es que no se pacta lo contrario ${ }^{30}$. ¿Cuál debe ser la regla que elija el derecho como regla predeterminada? La que las partes hubiesen elegido de haber negociado sobre esa materia y haber estado en capacidad de llegar a un arreglo ${ }^{31}$.

La justificación es sencilla. Contratar y negociar términos contractuales es costoso. Las partes incurren no pocas veces en altos costos de transacción para negociar cada uno de los términos que regularán el contrato que celebran.

Por lo tanto, para reducir los costos de transacción de negociar términos contractuales ineficientes, las reglas predeterminadas deben ser las que mejor repliquen o imiten los acuerdos que los hombres de negocio hubiesen acordado de haber, ex ante, negociado ellos mismos. Lo anterior significa que la regla default debe seguir la demanda de los hombres de negocio (nuestros clientes).

Pero no solo es costoso negociar esos términos contractuales. La economía conductual ha estudiado situaciones en las cuales incluso si es que las personas tuviesen incentivos para pactar en contra de reglas contractuales que son

30 SCHWARTZ, Alan. "The Default Rule Paradigm and the Limits of Contract Law". En Southern California Interdisciplinary Law Journal, vol. 3, 1993, p. 390. Consultado el 06 de julio de 2019: https:/ / digitalcommons.law.yale.edu/cgi/viewcontent.cgi?article=2079\&context=fss_papers

31 POSNER, Richard. Economic Analysis of Law, Massachusetts: Little, Brown and Company, 1986, 3ra edición, p. 372. 


\section{¿Escuchando mercaderes o escuchando abogados? \\ La regla sobre producción de documentos en el arbitraje comercial}

ineficientes para ellos, no lo harán por una tendencia natural a permanecer en el statu quo.

Explican Samuelson y Zeckhauser que las personas tienen una fuerte tendencia a permanecer en el statu quo. Las personas preferirán hacer nada o mantener su decisión previa o actual ${ }^{32}$. Según Kanheman, Knetsch y Thaler, esto se explica en que desde la perspectiva de un actor que aún no ha tomado una decisión, las desventajas de dejar dicho statu quo parecen mayores a las ventajas ${ }^{33}$. La economía conductual llama a esta tendencia el sesgo del statu quo, y se trata de una tendencia que ha sido probada en una serie de circunstancias ${ }^{34}$.

La influencia del statu quo sobre las reglas predeterminadas es considerable. Como señala Korobkin, por la tendencia de las personas a permanecer en el statu quo, el que los legisladores elijan una regla como predeterminada puede determinar que las partes no pacten en contra de dicha regla, sea que sea eficiente para ellos o no ${ }^{35}$. "El sesgo del statu quo sugiere que la diferencia entre las reglas contractuales default e imperativas podría ser de grado antes que de tipo - las reglas default pueden ser vistas como reglas 'casi-imperativas'" 36.

Entonces, elegir determinada regla como predeterminada no solo puede generar mayores costos a las partes, sino que en la práctica puede derivar en que las partes acepten reglas que no habrían pactado de haber negociado sobre ellas.

Esto es especialmente cierto en el arbitraje. A diferencia de las reglas contractuales sobre las cuales las partes suelen negociar; como lo hacen sobre el precio, los tiempos o límites de responsabilidad; lo cierto es que en cuanto a las reglas sobre arbitraje, las partes no suelen discutirlas en las negociaciones de sus contratos.

Ello explica que al convenio arbitral se le conozca como la "cláusula de media noche" 37 , pues suele ser la última cláusula que se redacta. Aun cuando sí se negocia, las partes suelen discutir aspectos del arbitraje como sede, extensión del convenio o institución arbitral, pero no discuten cuáles serán las reglas sobre la prueba aplicables. La regla sobre producción de documentos es una regla que difícilmente será negociada, lo que hace que la elección de la regla predeterminada sea inclusive más importante.

32 SAMUELSON, William y ZECKHAUSER, Richard. "Status Quo Bias in Decision Making". En Journal of Risk and Uncertainty, vol. 1, núm. 1, 1988, p. 7.

33 KAHNEMAN, Daniel; KNETSCH, Jack y THALER, Richard. "Anomalies: The Endowment Effect, Loss Aversion, and Status Quo Bias". En Journal of Economic Perspectives, vol. 5, núm. 1, 1991, pp. 197-198.

34 Ver: HARTMAN, Raymond; DOANE, Michael y WOO, CHI-KEUNG. "Consumer Rationality and the Status Quo"- En The Quarterly Journal of Economics, vol. 106, núm. 1, 1991, pp. 141-162.

35 KOROBKIN, Russel. "The Status Quo Bias and Contract Default Rules". En Cornell Law Review, vol. 83, 1988, pp. 664-665.

36 Ibíd., p. 665.

37 HOLTZ, Nancy. (Retd.), "Beware the Midnight Clause: Hold the Champagne?". En Judicial Arbitrarion and Mediation Services (JAMS), 2016. Consultado el 06 de julio de 2019: https://www.jamsadr.com/files/uploads/documents/articles/holtz-insidecounsel.combeware-the-midnight-clause.pdf 
Ahora bien ¿Cuál es la regla predeterminada sobre producción de documentos en el arbitraje comercial? Como las leyes arbitrales no suelen establecer reglas específicas sobre prueba y en ocasiones los reglamentos de las institucionales arbitrales tampoco, para responder esta pregunta debemos acudir a la práctica internacional en la materia.

Al respecto, las Reglas de la IBA sobre Práctica de Prueba en el Arbitraje Internacional son uno de los instrumentos más empleados en arbitrajes comerciales. Los tribunales arbitrales tienden a elegir como aplicables dichas reglas o disponer su aplicación supletoria. Por tanto, son un buen parámetro para determinar cuáles son las reglas sobre prueba supletorias en el arbitraje comercial.

Dichas Reglas establecen en su artículo 3 que las partes podrán solicitar a su contraparte una exhibición de documentos, que podrá ser realizada por documentos específicos o por categorías, siempre que cumplan con determinados requisitos. Por tanto, la regla default en las Reglas IBA es la producción de documentos.

Una parte que sea contraria a que se aplique esa regla solo tiene dos opciones: (i) pactar desde el contrato en contra de la producción de documentos o (ii) una vez constituido el tribunal arbitral, solicitar que se excluya la producción de documentos como regla aplicable. Sin embargo, cada una de estas opciones tiene problemas.

La primera, es que al momento de celebrar el contrato y en todo momento antes de iniciado el conflicto, las partes no tienen la información necesaria para saber si en un futuro arbitraje será conveniente pactar una regla sobre producción de documentos o no. Motivados por su tendencia al statu quo, pueden preferir que se aplique la regla supletoria. Además, casi con total seguridad al momento de celebrar el contrato las partes ni siquiera negociarán una regla sobre producción de documentos.

Sobre la segunda opción, si es que la regla default es la producción de documentos, a la parte contraria podría llamarle la atención que su contraparte solicite excluir la producción de documentos, lo que en teoría indicaría que esconden determinado documento que podría perjudicar su caso. Por lo tanto, es muy probable que se oponga a esa solicitud. En ese caso, será el Tribunal el que resuelva y usualmente optará por permanecer en el statu quo, optando por la regla default.

Entonces, observamos que una vez establecida la regla default sobre producción de documentos, esta regla es muy difícil de cambiar. Las partes usualmente se verán obligadas a tener una etapa de producción de documentos, incluso si ninguna está de acuerdo con dicha etapa. Esta etapa les causará un costo, que no se encontrará necesariamente justificado por el beneficio que viene a cambio. Este resultado no parece consistente con lo que los hombres de negocio demandarían.

IV. Escuchando a los mercaderes: ¿están justificando los costos de producción 
de los documentos en el arbitraje internacional?

En una encuesta realizada por la Queen Mary Univeristy of London en el año 2013 enfocada en las preferencias de compañías sobre el arbitraje internacional (“Queen Mary 2013"), el 52\% de encuestados señalaron que preferían altamente el arbitraje antes que cualquier otro método de resolución de controversias 38 :

\section{Rank the following dispute resolution mechanisms in order of preference.}

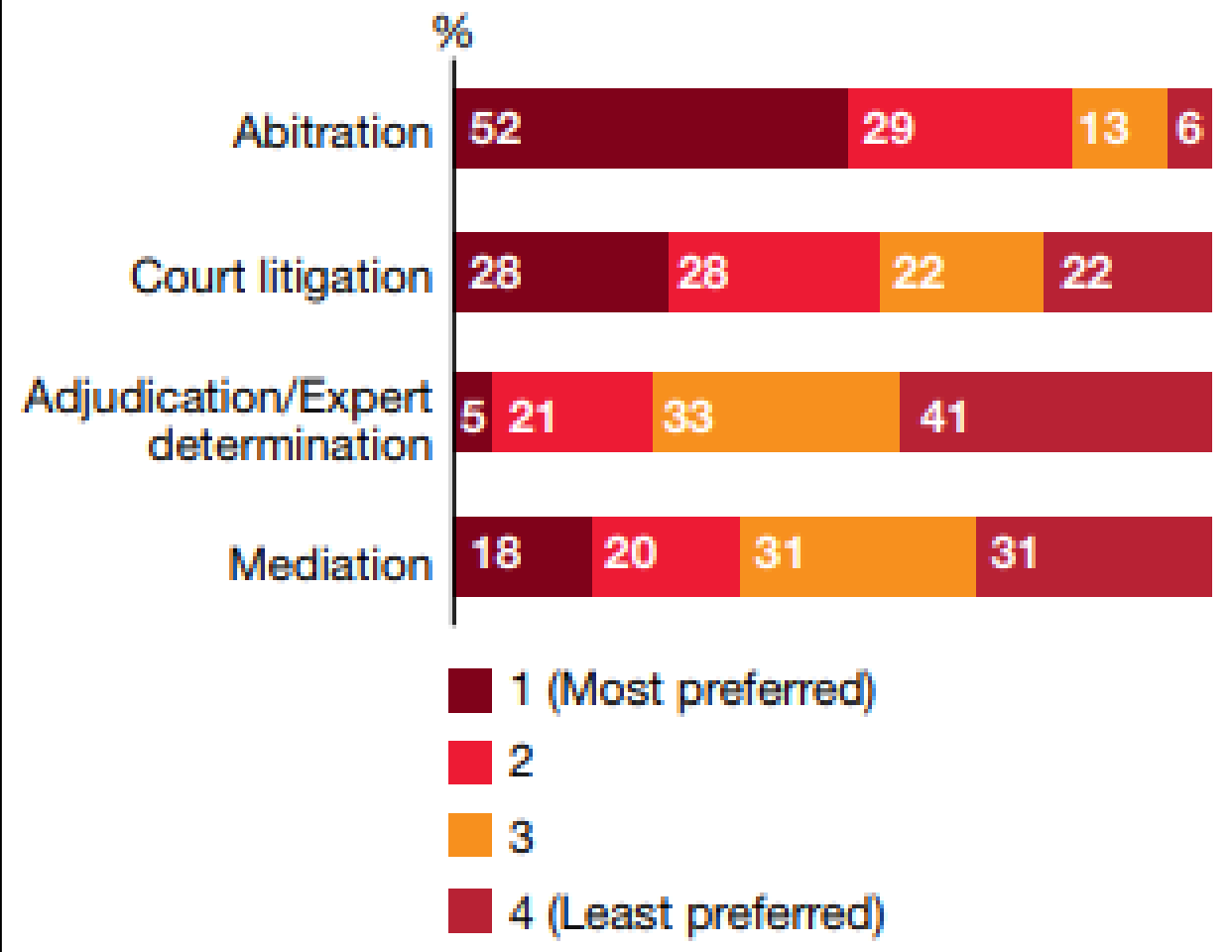

38 En: "The Choice of International Arbitration", encuesta realizada por la Queen Mary Univeristy of London en el año 2013, p. 6. Consultado el 06 de julio de 2019: https://www.pwc.com/gx/en/arbitration-dispute-resolution/assets/pwc-internationalarbitration-study.pdf 
Este porcentaje llega a $56 \%$ en primer lugar de alta preferencia a favor del arbitraje, cuando se trata de la resolución de disputas en la industria de energía ${ }^{39} ;$ y hasta un $68 \%$ de alta preferencia por el arbitraje, cuando se trata de la resolución de disputas en la industria de construcción ${ }^{40}$.

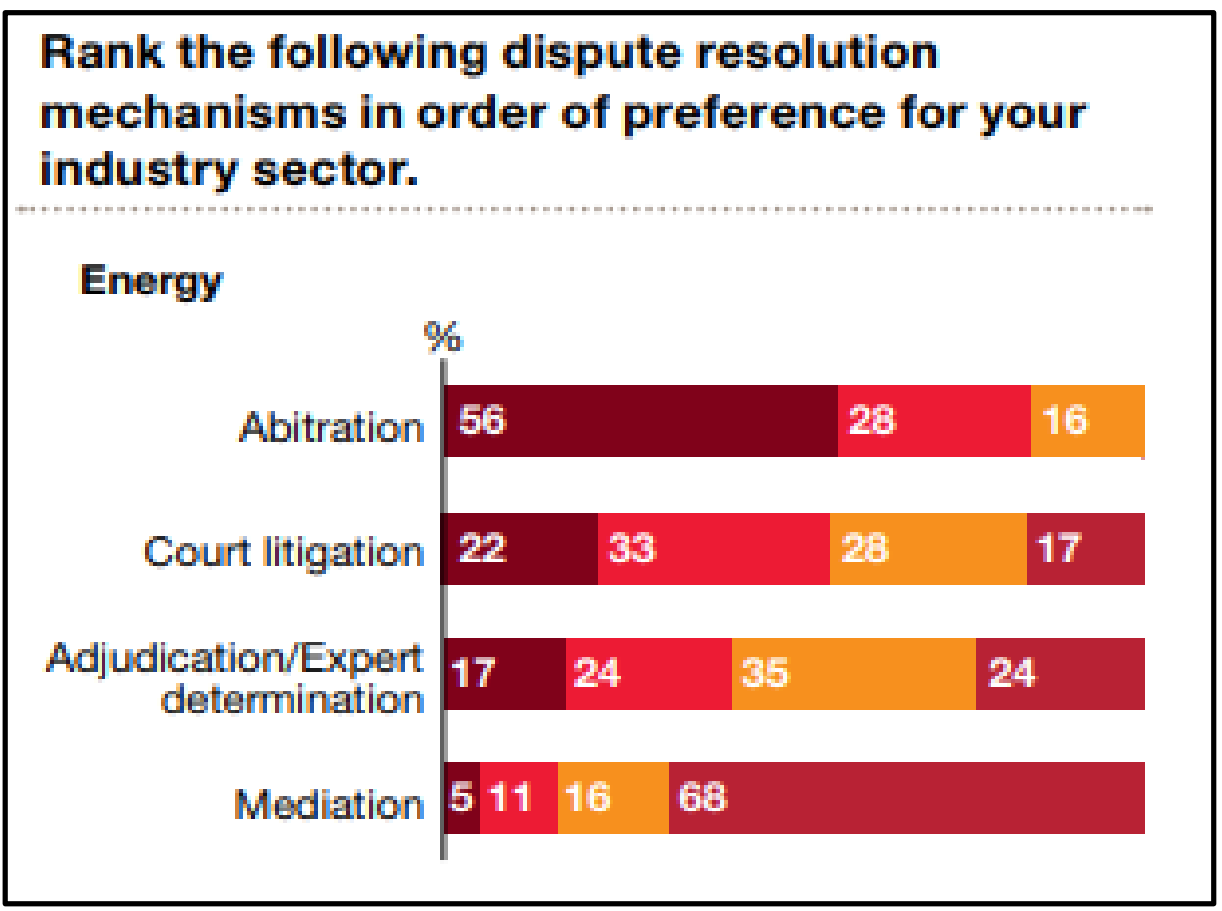

\section{Construction}

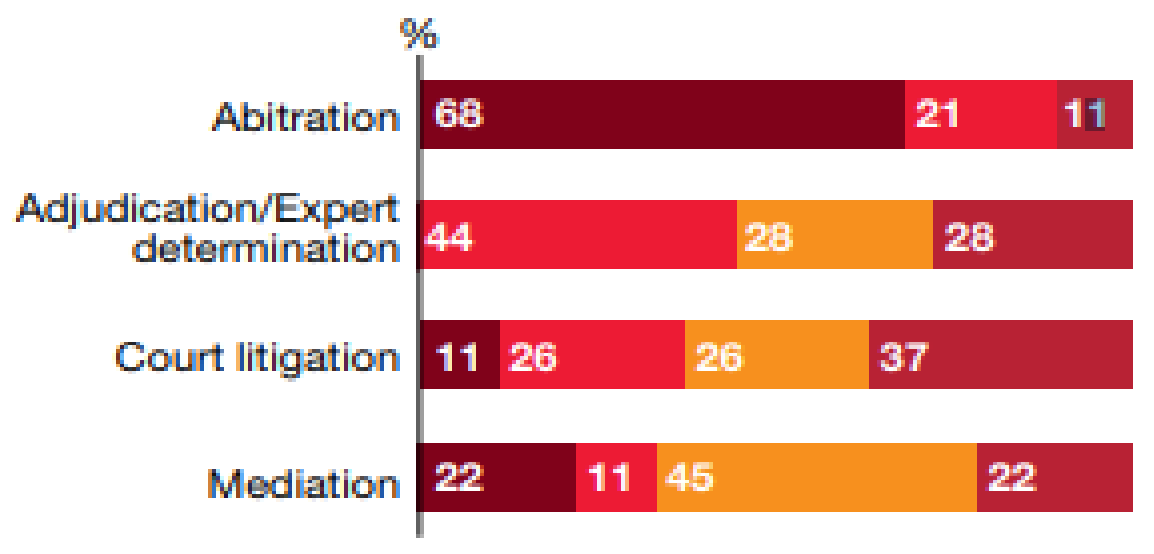

\section{1 (Most preferred)

39 En: “The Choice of International Arbitration", encuesta realizada por la Queen Mary Univeristy of London en el año 2013, p. 7. Consultado el 06 de julio de 2019: https://www.pwc.com/gx/en/arbitration-dispute-resolution/assets/pwc-internationalarbitration-study.pdf

40 En: "The Choice of International Arbitration", encuesta realizada por la Queen Mary Univeristy of London en el año 2013, p. 7. Consultado el 06 de julio de 2019: https://www.pwc.com/gx/en/arbitration-dispute-resolution/assets/pwc-internationalarbitration-study.pdf 
Luego, en una encuesta más reciente, elaborada por Queen Mary University of London y White \& Case del año 2018 (“Queen Mary 2018”), los abogados internos de las empresas encuestadas señalaron que hasta el 92\% preferían el arbitraje ya sea por sí solo o junto a otros mecanismos de resolución de controversias alternativos ${ }^{41}$ :

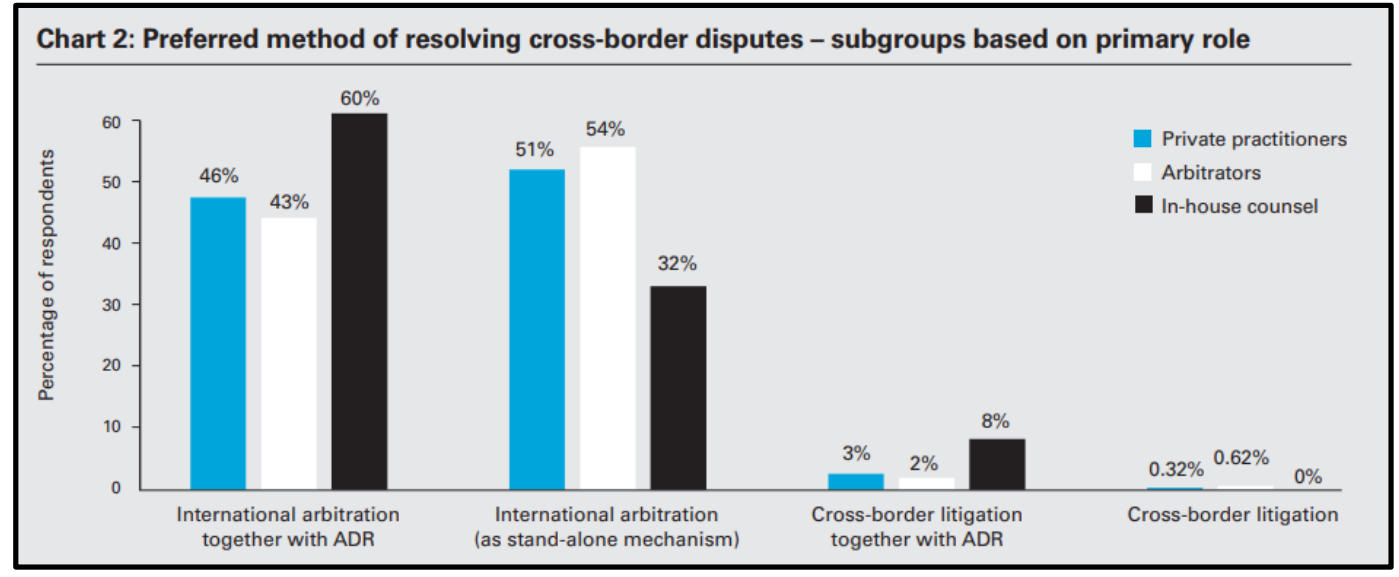

Los usuarios del arbitraje (los hombres de negocio) prefieren el arbitraje porque les permite reducir demoras y evitar procesos innecesariamente complejos. El arbitraje debe ser ese mecanismo rápido, eficiente y sin costos excesivos que buscan los usuarios de la industria arbitral ${ }^{42}$.

El problema surge cuando no escuchamos a los usuarios de nuestro producto. El problema aparece cuando no escuchamos las necesidades de los hombres de negocio. Las encuestas antes citadas nos dan luces sobre los principales problemas que enfrenta el arbitraje, conforme a la opinión de los hombres de negocio:

- De acuerdo con la encuesta Queen Mary 2013, la principal razón por la que los hombres de negocio no acuden al arbitraje (con el 22\% de los encuestados) son sus costos, mientras que la segunda razón es que suele durar más que otras alternativas (con el 17\%) $)^{43}$ :

41 En: “The Evolution of International Arbitration", encuesta elaborada por Queen Mary University of London y White \& Case del año 2018, p. 6. Consultado el 06 de julio de 2019: http:// www.arbitration.qmul.ac.uk/media/arbitration/docs/2018-International-ArbitrationSurvey-report.pdf

42 HO, Wendy. "Discovery in commercial arbitration proceedings". En Houston Law Review, vol. 34. 1997, p. 205.

43 En: "The Choice of International Arbitration", encuesta realizada por la Queen Mary Univeristy of London en el año 2013, p. 9. Consultado el 06 de julio de 2019: https://www.pwc.com/gx/en/arbitration-dispute-resolution/assets/pwc-internationalarbitration-study.pdf 


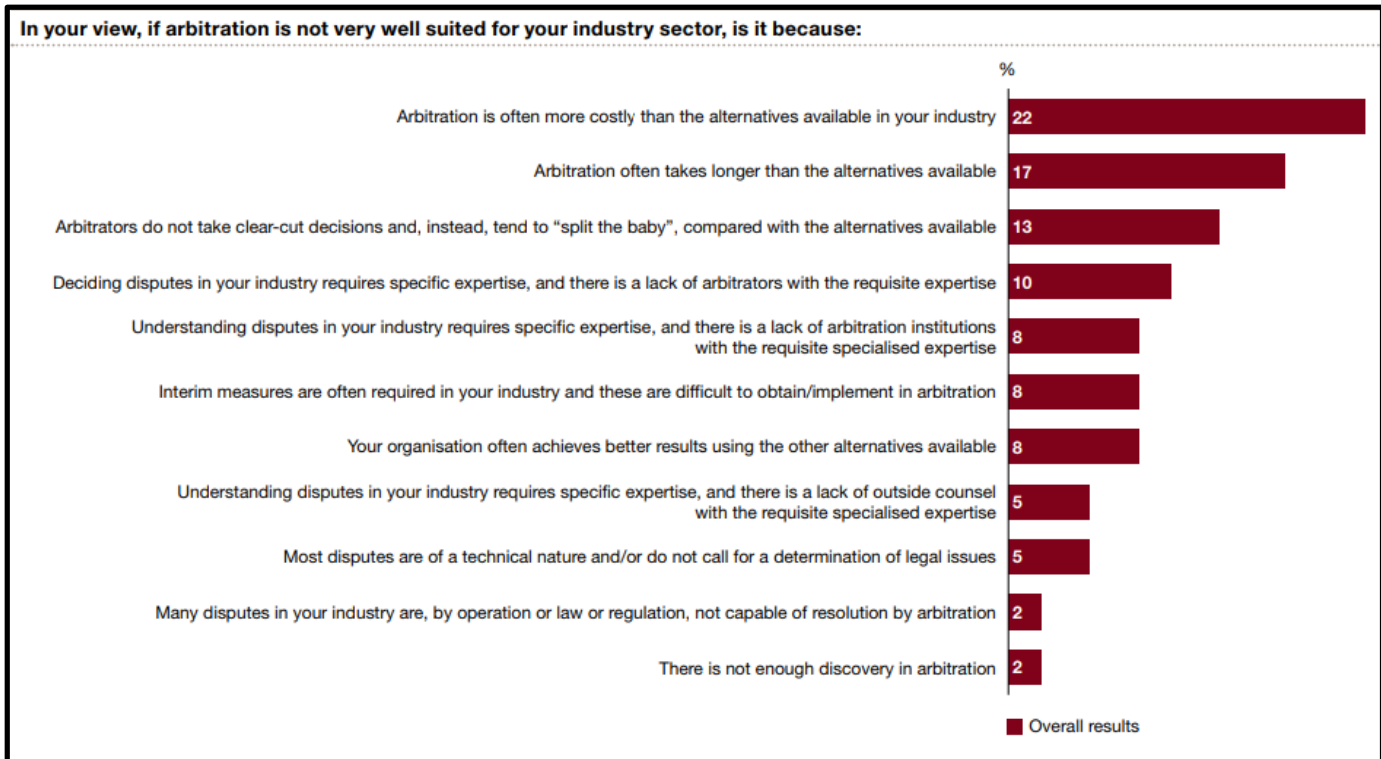

- 5 años después la encuesta Queen Mary 2018 nos plantea un escenario similar. Aunque dirigida a un grupo más grande (incluye abogados internos, pero también externos y árbitros), el 67\% de los encuestados considera que el costo es el peor problema del arbitraje (siendo la principal razón) y el 34\% que lo es su velocidad ${ }^{44}$ :

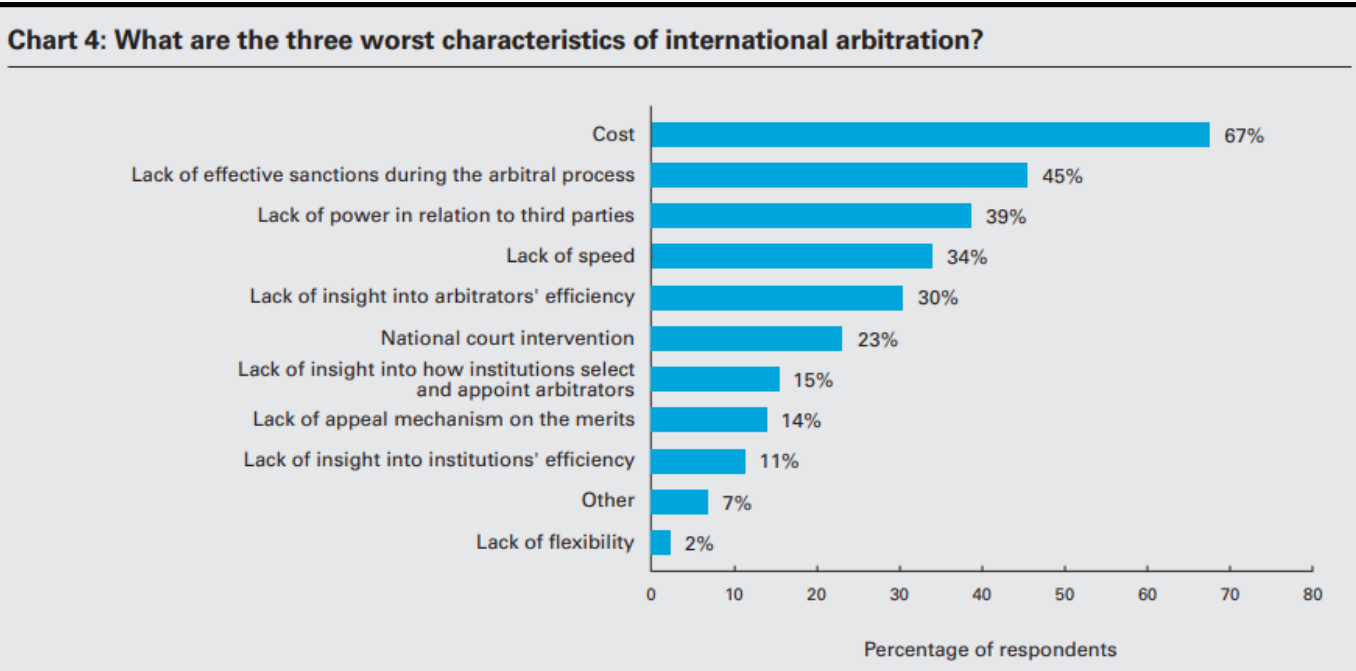

- Quizá la encuesta elaborada por Queen Mary Univeristy of London y White \& Case del año 2015 (“Queen Mary 2015”) lo expresa mejor: el 62\% de los

44 En: "The Evolution of International Arbitration", encuesta elaborada por Queen Mary University of London y White \& Case del año 2018, p. 8. Consultado el 06 de julio de 2019: http:// www.arbitration.qmul.ac.uk/media/arbitration/docs/2018-International-ArbitrationSurvey-report.pdf 
encuestados consideró que los abogados deberían trabajar junto a los abogados de su contraparte para limitar la producción de documentos45:

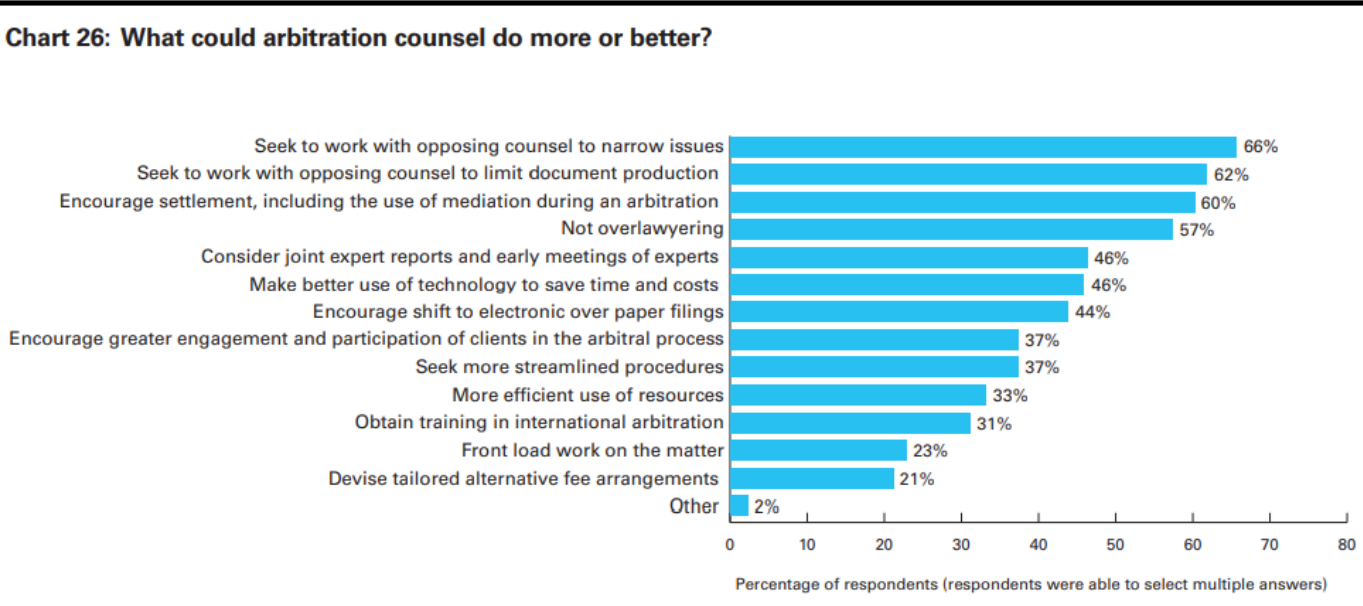

La conclusión es muy clara en el sentido que, por ahora, los hombres de negocio prefieren el arbitraje como mecanismo de resolución de sus disputas, pero al mismo tiempo manifiestan una alta preocupación por sus costos y demoras.

Dentro de esta preocupación por los altos costos y demoras, puede identificarse asimismo una especial preocupación por la etapa de producción de documentos como una de las principales causas de tales costos y demoras. Como se reporta en la encuesta sobre percepciones de la producción de documento en el arbitraje elaborado por la firma Berwein Leighton Paisner en el año 2013 (“BLP 2013”) 46:

- El 64\% de los encuestados consideró que la producción de documentos siempre o de manera frecuente añade costos de manera significativa. Otro 32\% señaló que lo hacía a veces. Es decir, el 96\% de los encuestados muestra preocupación por la etapa de producción de documentos y los costos que genera.

- El 53\% de los encuestados consideró que la producción de documentos siempre o de manera frecuente añade demoras de manera significativa. Otro 38\% señaló que lo hacía a veces. Es decir, el $91 \%$ de los encuestados manifestó preocupación por las demoras causadas por la etapa de producción de documentos.

45 En "Improvements and Innovations in International Arbitration", encuesta elaborada por Queen Mary Univeristy of London y White \& Case del año 2015, p. 30. Consultado el 06 de julio de 2019: http://www.arbitration.qmul.ac.uk/media/arbitration/docs/2015_International_Arbitration_ Survey.pdf

46 En: "The Choice of International Arbitration", encuesta realizada por la Queen Mary Univeristy of London en el año 2013, p. 10. Consultado el 06 de julio de 2019: https://www.pwc.com/gx/en/arbitration-dispute-resolution/assets/pwc-internationalarbitration-study.pdf 
De manera similar, en la encuesta elaborada por la Queen Mary University of London y White \& Case del 2010 (“Queen Mary 2010”) se reportó que la fase que contribuye más a la duración del arbitraje es la producción de documentos ${ }^{47}$ :

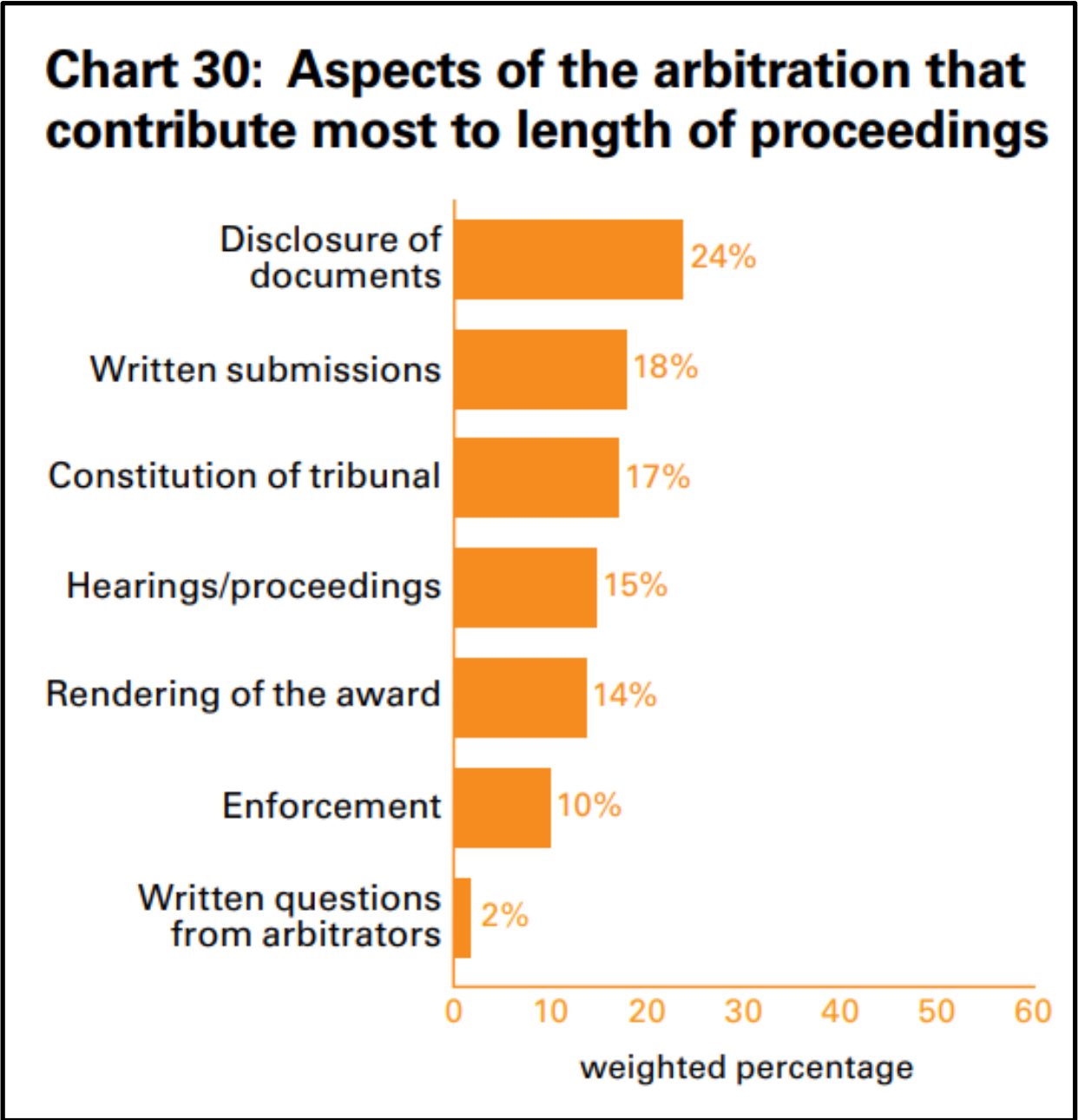

Los altos costos de la producción de documentos pueden explicarse en la tendencia que tienen las personas a interpretar nueva información de una manera consistente con sus ideas o conocimientos previos, de manera que les permita confirmarlos ${ }^{48}$. Esta tendencia recibe el nombre de sesgo de confirmación y tiene importantes repercusiones en la práctica del arbitraje.

En un procedimiento de producción de documentos, este sesgo puede llevar a los abogados de las partes a solicitar y buscar evidencia que confirme su teoría del caso, sin prestar atención a la información que podría contradecirla ${ }^{49}$. Las partes

47 En: "Choices in International Arbitration", encuesta elaborada por la Queen Mary University of London y White \& Case del 2010, p. 32. Consultado el 06 de julio de 2019: http://www.arbitration.qmul.ac.uk/media/arbitration/docs/2010_InternationalArbitrationSu rveyReport.pdf

48 ROBBENNOLT, Jennifer y STERNLIGHT, Jean. Psychology for lawyers: Understanding the human factors in negotiation, litigation, and decision making. Chicago: American Bar Association, 2013, p. 35.

49 RABIN, Matthew y SCHRAG, Joel. "First Impressions Matter: A Model of Confirmatory Bias". En The Quarterly Journal of Economics, vol. 114, núm. 1, 1999, p. 71. 


\section{¿Escuchando mercaderes o escuchando abogados? \\ La regla sobre producción de documentos en el arbitraje comercial}

podrían verse interpretando evidencia ambigua conforme a sus propias teorías, ambas concluyendo que apoya su caso. En consecuencia, podría llevar a que los abogados soliciten más documentos de los necesarios para apoyar su posición ${ }^{50}$.

En un experimento de Wistrich y Rachlinski, se condujo una simulación de un procedimiento de producción de documentos con 111 abogados, en donde se les advirtió expresamente que no soliciten más evidencia de la que fuese estrictamente necesaria. Pese a ello, el 75\% de los abogados solicitó más documentos de los requeridos ${ }^{51}$. La producción de documentos puede llevar a que las partes soliciten más información en busca de confirmar su teoría del caso, aumentando los costos en dinero y tiempo.

Frente a estos indudables altos costos causados por la etapa de producción de documentos, es sorprendente y preocupante que no exista evidencia que demuestre sus beneficios, tal y como se reporta en la encuesta Queen Mary 201552: "Algunos entrevistados notaron que los arbitrajes de manera creciente involucran listas amplias de problemas y solicitudes de documentos, incluso cuando estas puedan no ser necesarias para resolver su disputa."

Igualmente, las cifras reportadas en la encuesta BLP 2013 son francamente preocupantes. De los entrevistados solo el $8 \%$ señaló que los documentos obtenidos durante la producción de documentos habían contribuido a su caso de manera significativa en más del 75\% de casos; y el 63\% de los encuestados señaló que solo se habían visto beneficiados por la producción de documentos en menos del $25 \%$ de $\operatorname{casos}^{53}$.

Entonces, no cabe duda que la etapa de producción de documentos causa altísimos costos y sustanciales demoras al proceso, y que no existe evidencia que reporte que las partes del proceso considere que obtienen beneficios de la misma. Esta conclusión debería llevarnos a revisar si la regla default ha sido bien elegida o debe modificarse.

\section{La producción de documentos contradice principios del arbitraje comercial}

50 DE LA JARA, José María. “The irrationality of document production in international arbitration”. En Young ICCA Blog, 2016.

51 RACHLINSKI, Jeffrey y WISTRICH, Andrew. “How Lawyers' Intuitions Prolong Litigation”. En SSRN Electronic Journal, vol. 86, núm. 3, 2012, pp. 124-133.

52 En "Improvements and Innovations in International Arbitration", encuesta elaborada por Queen Mary Univeristy of London y White \& Case del año 2015, p. 30. Consultado el 06 de julio de 2019: http://www.arbitration.qmul.ac.uk/media/arbitration/docs/2015_International_Arbitration_. Survey.pdf

53 En: "Research based report on perceptions of document production in the arbitration process", encuesta elaborado por la firma Berwein Leighton Paisner en el año 2013, p. 10. Consultado el 06 de julio de 2019: https://www-staging.bclplaw.com/images/content/1/4/v2/147210/BLPInternational-Arbitration-Survey-2013.pdf 
Adicionalmente a los problemas anteriores, nuestra opinión es que la etapa de producción de documentos contradice diversos principios del arbitraje comercial.

\section{i. La autonomía de las partes}

Quizá el principio más importante del arbitraje comercial es la autonomía de las partes. El arbitraje permite que las partes acuerden todos los aspectos relativos al procedimiento. Si las partes desean incluir un procedimiento de producción de documentos en su arbitraje, deberían expresamente acordarlo. Como explican Redfern y Hunter:

"La autonomía de las partes es el principio guía para determinar el procedimiento a seguir en el arbitraje comercial internacional. Es un principio que ha sido recogido no solo en leyes nacionales sino también por instituciones y organizaciones arbitrales internacionales. La historia de la Ley Modelo muestra que el principio fue adoptado sin oposición" 54 .

Hemos explicado que si la producción de documentos es la regla predeterminada en la práctica se vuelve imposible que las partes pacten en contra. Al momento de celebrar el contrato las partes no piensan en las reglas de procedimiento aplicables al arbitraje, menos saben que deben pactar en contra de la producción de documentos si quieren excluirla. Una vez iniciado el arbitraje, si una parte solicita al tribunal arbitral que se excluya la producción de documentos, la otra parte puede pensar que busca esconder alguna prueba y oponerse.

Por lo tanto, obligar a las partes a pactar en contra si quieren excluir la producción de documentos deriva en que exista producción de documentos de todas formas, pese a que ninguna de las partes pueda estar de acuerdo con ello. Eso contradice la autonomía de las partes y no debería ser aceptado como regla predeterminada en el arbitraje.

\section{ii. Carga de la prueba}

En el arbitraje como regla general, cada parte tiene la carga de probar su caso ${ }^{55}$. Ninguna parte debería verse obligada a probar el caso de su contraparte, y menos a producir evidencia en contra de su propio caso. No debería ser controvertido que la producción de documentos, al permitir a las partes basar su caso en evidencia distinta a la propia, contradice la carga de la prueba. Esto lleva que una parte pueda iniciar un arbitraje pese a que no cuenta con la evidencia necesaria para probar su caso, obligando a su contraparte a verse envuelta en un arbitraje que podría haberse evitado.

54 REDFERN, Alan y HUNTER, Martin con BLACKABY, Nigel y PARTASIDES, Constantine. Law and Practice of International Commercial Arbitration. Londres: Sweet and Maxwell, 2004, 4ta Edición, 2004, p. 315.

55 "Informe de la Comisión de las Naciones Unidas para el Derecho Mercantil sobre la labor realizada en su noveno periodo de sesiones". A/31/17 (12 de abril a 7 de mayo de 1976), Anexo II, párrafo 116. Consultado el 06 de julio de 2019: https://undocs.org/es/A/31/17(SUPP) 


\section{¿Escuchando mercaderes o escuchando abogados? \\ La regla sobre producción de documentos en el arbitraje comercial}

Al momento de comentar sobre la importancia del discovery en el proceso judicial del common law observamos que una de las razones fundamentales para la existencia y necesidad de esta institución era la estructura propia de los procesos judiciales norteamericanos e ingleses. Ahora bien, si es que por circunstancias particulares las partes en un arbitraje consideran que requieren de una fase de producción de documentos pese a que ello va en contra de la carga de la prueba, siempre podrán pactarlo. Pero la producción de documentos no debería tenerse como regla predeterminada pues ello justamente va contra la carga de la prueba (y la autonomía privada).

\section{iii. Eficiencia en tiempo}

Igualmente, la producción de documentos contradice el objetivo de que el arbitraje sea un mecanismo de resolución de controversias rápido y eficiente. En este trabajo hemos comentado al respecto lo siguiente:

- De acuerdo con la encuesta de BLP 201356, el 53\% de los encuestados consideró que la producción de documentos siempre o de manera frecuente añade demoras de manera significativa. Otro 38\% señaló que lo hacía a veces. Es decir, el $91 \%$ de los encuestados manifestaron preocupación por las demoras generadas por la etapa de producción de documentos.

- En la encuesta elaborada por la Queen Mary 2010 se reportó que la fase que contribuye más a la duración del arbitraje es la producción de documentos ${ }^{57}$.

Por ello algunos autores analizando la institución de producción de documentos han concluido que genera la grave amenaza de paralizar los procedimientos ${ }^{58}$ :

“La sola aceptación de este mecanismo en el arbitraje internacional puede ser visto como abrir una Caja de Pandora, en teoría, y a veces en la práctica. Cualquiera que sea la posición prima facie sobre la producción de documentos (a favor o en contra), los últimos diez años han visto una preocupación común creciente y compartida acerca de que este mecanismo pueda ser, y que a veces de hecho lo fue, mutando hacia un "monstruo" o "tsunami", dado el enorme número de documentos resultantes de ese proceso, que no solo son onerosos para la parte que los produce de guardar, recoger, revisar, clasificar y entregar, sino para la otra parte de digerir y tratar eficientemente dentro del tiempo limitado asignado por el

56 En: "Research based report on perceptions of document production in the arbitration process", encuesta elaborado por la firma Berwein Leighton Paisner en el año 2013, p. 10. Consultado el 06 de julio de 2019: https://www-staging.bclplaw.com/images/content/1/4/v2/147210/BLPInternational-Arbitration-Survey-2013.pdf

57 En: "Choices in International Arbitration", encuesta elaborada por la Queen Mary University of London y White \& Case del 2010, p. 32. Consultado el 06 de julio de 2019: http://www.arbitration.qmul.ac.uk/media/arbitration/docs/2010_InternationalArbitrationSu rveyReport.pdf

58 EL-AHDAB, Jalal y BOUCHENAKI, Amal. “Discovery in International Arbitration: A Foreign Creature for Civil Lawyers?". En VAN DEN BERG, Albert Jan (ed.), Arbitration Advocacy in Changing Times, Países Bajos: Kluewer Law International, 2011, pp. 65 - 113. 
calendario procesal establecido por el tribunal."

Nuevamente, si las partes son las que quieren pasar por un proceso de producción de documentos con los costos en tiempo que eso implica, pueden hacer y pactarlo expresamente.

\section{iv. Eficiencia en costos}

También hemos comentado sobre el alto impacto en costos que genera la producción de documentos como regla predeterminada. La principal preocupación de los hombres de negocio que enfrentan un arbitraje son sus costos. Conforme a la encuesta BLP 201359, el 64\% de los encuestados consideró que la producción de documentos siempre o de manera frecuente añade costos de manera significativa. Otro 32\% señaló que lo hacía a veces. Es decir, el 96\% de los encuestados mostraron preocupación por los costos que genera la producción de documentos.

Conforme a la encuesta Queen Mary 2013, la principal preocupación de las partes de un arbitraje son los costos del proceso. Además, los encuestados indican que no les preocupa que no exista discovery ${ }^{60}$ :

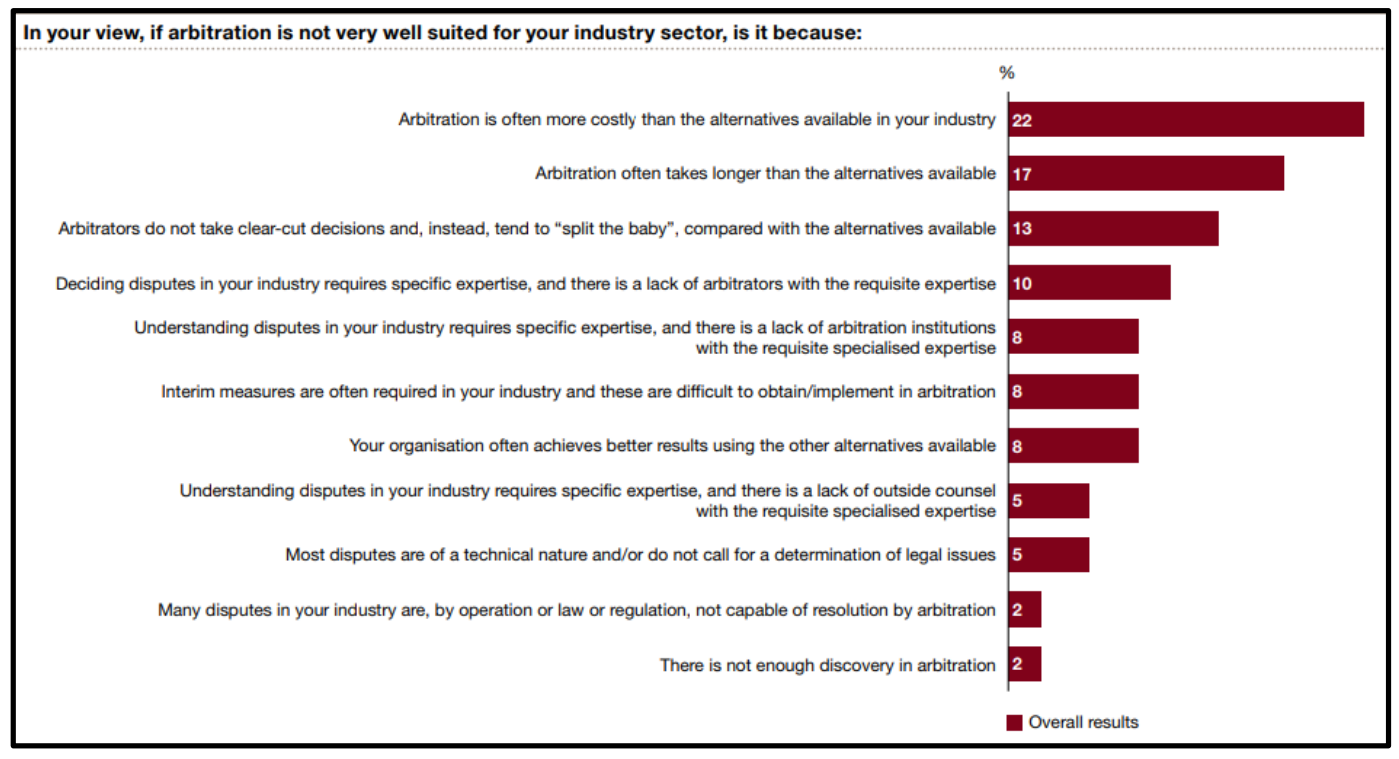

Es muy claro entonces que la producción de documentos no es un aspecto significativo para los usuarios del arbitraje, y sin embargo la actual regla predeterminada obliga a las partes a invertir tiempo y dinero en ello.

\section{v. Confidencialidad}

Finalmente, la producción de documentos como regla predeterminaba podría

59 En: "Research based report on perceptions of document production in the arbitration process", encuesta elaborado por la firma Berwein Leighton Paisner en el año 2013, p. 10. Consultado el 06 de julio de 2019: https://www-staging.bclplaw.com/images/content/1/4/v2/147210/BLPInternational-Arbitration-Survey-2013.pdf

60 En: "The Choice of International Arbitration", encuesta realizada por la Queen Mary Univeristy of London en el año 2013, p. 9. Consultado el 06 de julio de 2019: https://www.pwc.com/gx/en/arbitration-dispute-resolution/assets/pwc-internationalarbitration-study.pdf 


\section{¿Escuchando mercaderes o escuchando abogados? \\ La regla sobre producción de documentos en el arbitraje comercial}

atentar también contra la confidencialidad del arbitraje. Por supuesto, confidencialidad no significa solamente la confidencialidad de los procedimientos. Implica también la información confidencial que tiene cada parte y que puede ser revelada durante el proceso de producción de documentos. Especialmente cuando muchos arbitrajes suelen involucrar empresas competidoras, que podrían verse beneficiadas de acceder a información confidencial "por accidente".

\section{Escuchando a los mercaderes: ¿cuál debería ser la regla default?}

Considerando todo lo anterior, ¿cuál debería ser la regla default sobre la producción de documentos? Ya hemos señalado la importancia que tiene elegir una regla default adecuada y que esta debe ser aquella que los usuarios del arbitraje pactarían si negociaran esa regla. La regla debe responder a las demandas de los hombres de negocios y, por tanto, debería contribuir a lograr un proceso eficiente de solución de controversias.

No tenemos duda que, si los hombres de negocio pudiesen negociar ex ante, definitivamente no elegirían una regla de producción de documentos amplia como predeterminada, considerando la demora y los costos que genera en el procedimiento arbitral, y especialmente tomando en cuenta las reducidas y poco probables ganancias que produce. Nuestro pronóstico es que elegirían la regla que introduce más eficiencia al proceso de resolución de controversias.

Elegirían una regla con beneficios claros y costos justificados. En la producción de documentos esa regla sería aquella que permite la producción de documentos de manera restringida, limitándola a la producción de documentos específicos (antes que a la producción de categorías de documentos).

En este punto es interesante revisar la práctica de varios países de la tradición del civil law, pues nos ofrecen luces sobre cómo podría funcionar una regla de este tipo. En primer lugar, notamos que salvo excepciones ${ }^{61}$ las leyes arbitrales nacionales en países del civil law no regulan expresamente la producción de documentos. Por el contrario, la aproximación general suele ser que no se aborde el tema de la producción de documentos ${ }^{62}$.

Sin embargo, la práctica en estos países ofrece luces interesantes. Como reportan Richard Kreindler, Thomas Kopp y Patrick Gerardy en la Guía de Arbitraje de la IBA sobre Alemania actualizada en el 201863, "la aproximación alemana al discovery es restrictiva - tanto en litigación como en arbitraje" 64 . Señalan que los árbitros

61 Sí lo hace el Código Procesal Civil Francés, Artículo 1467.3. ("If a party is in possession of an item of evidence, the arbitral tribunal may enjoin that party to produce it, determine the manner in which it is to be produced and, if necessary, attach penalties to such injunction.").

62 BORN, Gary. International Commercial Arbitration. Países Bajos: Kluwer Law Interntional 2014, 2da edición, p. 2330.

63 Las Guías de Arbitraje de la IBA son reportes preparados por especialistas en arbitraje de cada país, comentando el estado del arbitraje de ese país en ese momento. Cada guía cuenta con una sección dedicada a la producción de documentos y sub-preguntas al respecto.

64 Guía de Arbitraje de la IBA sobre Alemania actualizada en el 2018, p. 11 
alemanes serían más contrarios a ordenar una producción de documentos que sus colegas de otras jurisdicciones, e inclusive donde sí lo ordenen "se obligará al solicitante que especifique los documentos relevantes y su contenido de manera considerablemente detallada" 65 . La regla de la práctica alemana es producción de documentos limitada, y limitada a documentos específicos y detallados.

En Italia, la situación es simular. Señalan Luca Radicati y Michele Sabatini en la Guía de Arbitraje de la IBA sobre Italia actualizada en el 2018, que pese a que no existen reglas específicas sobre producción de documentos "el discovery en el procedimiento arbitral generalmente no será particularmente extensivo ni intrusivo"66. Por el contrario, salvo que alguna de las partes involucradas sea del common law, la producción de documentos raramente será solicitada ${ }^{67}$.

Como reportan Ilya Nikiforov, Victor Radnaev, Olga Tsvetkova y Mikhail Samoylov en la Guía de Arbitraje de la IBA sobre Rusia actualizada al 2018, en este país la regla se repite. Los árbitros conceden solicitudes de producción de documentos que son "identificados con un alto grado de especificidad (en oposición a clases o categorías de documentos)" 68 . Reglas similares se derivan de la práctica de países como Bulgaria ${ }^{69}$, Rumania ${ }^{70}$ y Ucrania ${ }^{71}$.

Como se puede observar la regla es sencilla, con beneficios ciertos y costos justificados. Se limita la producción de documentos a la producción de documentos específicos identificados de manera detallada. Se dejan de lado y no se aceptan los pedidos categorías de documentos, o los pedidos revelación general o de discovery al estilo del common law.

Nuestra opinión es que esa es la regla que resulta de escuchar las necesidades de los hombres de negocios. No tenemos duda que esta en una mejor regla que la regla predeterminada de producción de documentos amplia. Implica menos horas facturables de abogados. Con ello, favorece procesos más rápidos y menos costos.

\section{Conclusión: hagamos del arbitraje el mejor mecanismo de resolución de controversias que existe}

En 1947 cuando la Segunda Guerra Mundial había terminado hacía muy poco, Winston Churchill, en ese momento Ex Primer Ministro del Reino Unido, defendía la democracia con una frase que todavía hoy es muy conocida: “La democracia es la peor forma de Gobierno, excepto por todas aquellas formas que han sido probadas en todo momento." La frase de Churchill ilustra nuestro caso pues parafraseándola nos podríamos referir a los problemas del arbitraje que comentamos en este trabajo y concluir que “El arbitraje es el peor mecanismo de

65 Guía de Arbitraje de la IBA sobre Alemania actualizada en el 2018, p. 12.

66 Guía de Arbitraje de la IBA sobre Italia actualizada en el 2018, p. 15.

67 Guía de Arbitraje de la IBA sobre Italia actualizada en el 2018, p. 15.

68 Guía de Arbitraje de la IBA sobre Rusia actualizada en el 2018, p. 12.

69 Guía de Arbitraje de la IBA sobre Bulgaria actualizada en el 2018, p. 11.

70 Guía de Arbitraje de la IBA sobre Rumania actualizada en el 2013, p. 10.

71 Guía de Arbitraje de la IBA sobre Ucrania actualizada en el 2012, p. 12. 


\section{¿Escuchando mercaderes o escuchando abogados? \\ La regla sobre producción de documentos en el arbitraje comercial}

resolución de disputas, excepto por todos aquellos mecanismos que han sido probados en todo momento"72. En efecto, pese a sus costos, tiempos, y a las ineficiencias derivadas de la producción de documentos, el arbitraje sigue siendo el mecanismo preferido por los hombres de negocios. El arbitraje todavía es el mecanismo preferido, no tanto por sus virtudes, sino porque sus alternativas son aún peores.

No cabe duda que el mayor riesgo que hoy enfrenta el arbitraje somos los abogados. Los abogados controlamos el proceso y muchas veces lo complicamos, encareciéndolo, olvidando las necesidades de los hombres de negocios (nuestros clientes). En la producción de documentos es muy claro que hemos dejado de considerar las necesidades de los hombres de negocios. No puede descartarse que en lo que a producción de documentos se refiere, se está prefiriendo un diseño del que los abogados derivamos claros beneficios. No obstante, conforme a la evidencia que hemos revisado en este trabajo, nuestros clientes muestran preocupación por el resultado.

Pese a todo, no parece que los abogados seamos conscientes de esta situación. No sugerimos que los abogados tengamos estas reglas con el objetivo de obtener beneficios a sabiendas de que perjudica a nuestros clientes. Por el contrario, parece que el camino ha sido más bien motivado por sesgos inconscientes de los que no hemos podido escapar.

Por un lado, por el temor de perder de vista documentos que podrían ser relevantes estamos buscando evidencia que confirme nuestra teoría del caso, aun cuando sean documentos ambiguos o que no aportan nueva información ${ }^{73}$. Por el sesgo de confirmación estamos buscando más información de la que necesitamos ${ }^{74}$, incrementando los costos del arbitraje pese a que la evidencia sugiere que no encontraremos ninguna "pistola humeante" que defina nuestro caso $^{75}$.

Por el otro, estamos confiando en exceso en el statu quo del arbitraje comercial, en el cual la regla que se ha establecido como predeterminada es la producción de documentos amplia. Por el sesgo de statu quo no pactamos o solicitamos una regla distinta, aun cuando sería beneficioso para ambas partes ${ }^{76}$. Lo que perdemos de

72 Este parafraseo fue acuñado por primera vez en la encuesta de arbitraje internacional de la Universidad de Londres Queen Mary y White \& Case del año 2015. Ver: En “Improvements and Innovations in International Arbitration", encuesta elaborada por Queen Mary Univeristy of London y White \& Case del año 2015, p. 10. Consultado el 06 de julio de 2019: http://www.arbitration.qmul.ac.uk/media/arbitration/docs/2015_International_Arbitration Survey.pdf

73 RABIN, Matthew y SCHRAG, Joel. "First Impressions Matter: A Model of Confirmatory Bias". En The Quarterly Journal of Economics, vol. 114, núm. 1, 1999.

74 RACHLINSKI, Jeffrey y WISTRICH, Andrew. "How Lawyers' Intuitions Prolong Litigation”. En SSRN Electronic Journal, vol. 86, núm. 3, 2012.

75 ROGERS, Andrew. "Improving Procedures for Discovery and Documentary Evidence". En VAN DEN BERG, Albert Jan (ed.), Planning Efficient Arbitration Proceedings: The Law Applicable in International Arbitration, Países Bajos: Kluwer Law International, 1996, p. 137.

76 KOROBKIN, Russel. "The Status Quo Bias and Contract Default Rules". En Cornell Law Review, vol. 83,1988, p. 665 . 
vista es que esta regla responde a un contexto específico en países de common law, en el cual por el objetivo y estructura del proceso judicial tiene total sentido. No por el contrario en procesos y estructuras que responden a otros principios, como el de autonomía de las partes y carga de la prueba, que en cambio sí tienen lugar en el arbitraje.

Necesitamos volver a escuchar a los hombres de negocio y diseñar "el producto" a la medida de sus necesidades. Lo que está en juego es la satisfacción de los intereses de nuestros clientes y, con ello, la consolidación del sistema arbitral como el mejor sistema de resolución de disputas. Para ese fin es fundamental, ante el conflicto, poner los intereses de nuestros clientes por encima de los nuestros. 